\title{
"Quise entonces fumar". El opio en César Vallejo y Pablo Neruda: rutas asiáticas de experimentación
}

\author{
"Then I wanted to smoke". Opium in César Vallejo \\ and Pablo Neruda: Asian Roads of Experimentation
}

\section{Francisco Leal}

Foreign Languages and Literatures, Colorado State University. Fort Collins, USA. francisco.Leal@colostate.edu

\section{Resumen}

César Vallejo y Pablo Neruda fuman el opio cuando están escribiendo Trilce (1922) y Residencia en la tierra (1935), respectivamente. No mencionan la droga en sus colecciones, pero ambos escriben al margen de su obra literaria textos sobre su experiencia narcótica: un cuento-testimonio, en Vallejo; confesiones y memorias, en Neruda. Los dos poetas igualmente describen al opio como una puerta de valoración de lo asiático, sus costumbres y habitantes. Por medio del análisis de los escritos sobre el opio de Vallejo en su cuento "Cera" de Escalas melografiadas (1923) y de Neruda en su poema "El opio en el Este" de Memorial de Isla negra (1964), este artículo investiga, por un lado, los conceptos estéticos que se revelan en las relaciones del opio con la escritura de estos poetas, y por otro lado, las relaciones del opio con lo asiático que establecen los escritores como una forma de definir sus concepciones políticas.

Palabras clave: César Vallejo, Pablo Neruda, poesía, opio, orientalismo, estéticas bajo la influencia de drogas.

\section{Abstract}

César Vallejo and Pablo Neruda smoked opium when they are writing Trilce (1922) and Residence on Earth (1935), respectively. There is no mention of the drug in their poetry collections, but both wrote literary texts telling their narcotic experience: a short-story in Vallejo; confessions and memoirs, in Neruda. The two poets also described the opium as a door to Asia, its customs and people. Through an analysis of Vallejo's short story, "Cera", included in Escalas Melografiadas (1923) and Neruda's poem "El opio en el Este", included in Memorial de Isla negra (1964), this paper investigates, on the one hand, the aesthetic's concepts revealed thru the relationships between opium and the writing of these poets, and on the other hand, the connections thru opium with the Asia ad way to define the political views of the poets.

Keywords: César Vallejo, Pablo Neruda, Poetry, Opium, Orientalism, Aesthetics under the influence of drugs. 


\section{César Vallejo, Pablo Neruda y el opio de Asia}

César Vallejo y Neruda conforman, por muchas razones, una de las parejas más peculiares de la poesía hispanoamericana. La radical experimentación de Trilce (1922) del primero y de Residencia en la tierra (1935) del segundo, o el compromiso político y poético en España aparta de mí este cáliz y España en el corazón de los mismos autores, son algunos ejemplos de su influyente singularidad que, como precisa Saúl Yurkievich, los lleva a ser considerados como principales "fundadores de la nueva poesía latinoamericana”. Pero también se relacionan más subterráneamente por el hecho de haber fumado opio y haber escrito sobre él, por lo que considero que investigarlos desde lo que escriben sobre esa droga que tienen en común y lo que se resalta de los trabajos de estos poetas por medio de las descripciones que hacen de ella, permite analizarlos desde un ángulo poco estudiado: el del opio. Más que un anecdótico detalle biográfico, el opio en esto poetas muestra un escenario textual que trasluce sus perspectivas sobre la extranjería asiática, lo propio, lo impropio, lo bello, lo repulsivo; es decir, en sus comentarios sobre el opio se presentan discusiones del ámbito poético, político y también subjetivo que precisamente se revelan en sus comentarios narcóticos. Lo que escribieron los poetas sobre el opio, por lo tanto, es una manera de captar las formas en que relacionan esta experiencia narcótica con sus trabajos literarios, como también las apreciaciones que hacen de sus usuarios y lugares de consumo como una manera de resaltar sus sensibilidades sociales y políticas.

Pablo Neruda y César Vallejo exploran en su juventud la embriaguez en general como experimentación subjetiva y poética. Junto con otros altibajos amorosos, monetarios o laborales, lo hacen como parte del cultivo de un perfil estético en contrastada distancia a la productividad y buenos gustos de la burguesía. En los días (y noches) de Trilce (1922), Vallejo frecuentaba los fumaderos de opio en los barrios chinos de Lima. Neruda hace lo mismo en Asia en sus días de cónsul cuando componía Residencia en la tierra (1935). Pero pese a ese dato, resaltado tanto por los biógrafos como por los propios poetas, ni Neruda y ni Vallejo le asignan un peso poético al opio en la configuración de sus libros más radicales. Por el contrario: borran cualquier evidente conexión entre el narcótico y su escritura. La poesía de Vallejo sólo insinúa esta droga una sola vez en unas "píldoras de opio" en un contexto médico y doméstico en los póstumos Poemas humanos (Obras 313). Neruda también borra nominativamente al opio de Residencia en la tierra, pese a que se refiere en esa colección al menos trece veces a las amapolas, la flor del opio. Sin embargo, tanto para Vallejo como para Neruda, el opio representa un objeto simbólico especialmente cargado que les permite no solo drogarse sino también evaluar sus aventuras extranjeras. En "Cera" de Escalas melografiadas (1923) de Vallejo, y en el poema "El opio en el Este" de Memorial de Isla negra de Neruda (1964), el opio se resalta como un escenario que traza significativas distinciones, fronteras y jerarquías, y es el lugar desde el cual los poetas plantean sus perspectivas sociales y poéticas. Tanto Vallejo como Neruda rechazarán el furor 
bohemio y ensimismado de los años formativos en que escriben Trilce y Residencia, y lo reemplazarán por uno comunitario y político, y en ese significativo cambio, la embriaguez, sobre todo la causada por el opio, queda denotada en la frontera enemiga de esta nueva delimitación subjetiva, poética y política.

\section{Bajo fuertes influencias occidentales se consume el opio asiático}

La prohibición y la curiosidad en la literatura han rodeado el opio, pero no el silencio ${ }^{1}$. Una de las primeras filmaciones de la historia del cine, producida y realizada en 1894 en el estudio de Thomas Edison, se titula Chinese Opium Den, u Opium Joint [fumadero chino de opio]. La cinta, por medio de sus pioneras filmaciones, reproducía para el curioso ojo occidental, exóticos lugares de ebriedad asiática. Esta película desapareció, pero la idea de usar el opio para retratar "orientalistamente" (Edward Said dixit) lo asiático para satisfacer las inquietudes y ansiedades de las burguesías occidentales, sigue siendo una constante a la hora de representarlo artística o poéticamente, y es lo que, en parte, se resalta en los textos drogados de los poetas de este estudio. El opio en Neruda y Vallejo se revela literariamente como una mercancía narcótica creadora de paraísos artificiales y al mismo tiempo como un objeto fetichizado que acarrea narrativas de culturas y barbaries, inspiraciones y rechazos, prohibiciones y persecuciones, sueños y también pesadillas en el humo de los poetas. El opio en Vallejo y Neruda representa un confuso crisol que permite la reunión de comentarios de diferentes naturalezas: la autonomía moral y creativa del arte, el viaje interior y las inspiraciones narcóticas, por lo tanto, se mezclan imaginariamente con discursos y representaciones exotistas en un territorio donde las fronteras creativas de la estética y las prescriptivas de la política se juntan y confunden.

1 La bibliografía relativa al opio en general y sobre el opio en la literatura en particular es extensa y fascinante. Sobre el cruce del narcótico con las letras Europeas y de Norteamérica, un ilustrativo libro es el de Marcus Boon, The Road of Excess, en especial su capítulo "Addicted to Nothingness", como también, desde una escritura más experimental, el trabajo de Sadie Plant, Writing on Drugs, en especial el capítulo "Ghosts". El trabajo de Marta Herrero-Gil El paraíso de los escritores ebrios hace un buen catastro sobre los escritores modernistas de Hispanoamérica y las drogas que usaron y sobre las que escribieron. El libro Sister of extreme Women Writing on the Drug Experience, editado por Cynthia Palmer y Michael Horowitz es especialmente informativo en un punto que suele ser oscuro: la relación de las escritoras con los narcóticos. Sobre el opio en general, su historia, su prohibición, sus usos sociales, sus perfiles culturales y legales, entre otros temas, dos libros que consideré muy útiles para esta investigación fueron: Historia General de las Drogas de Antonio Escohotado, y La búsqueda del olvido de Richard Davenport-Hines, sobre todo de éste último los capítulos "Opio durante la Ilustración" y "Los albores de la prohibición". Del libro de Escohotado destaco que es una de las historias más completas, informativas y valientes sobre las drogas en cualquier lengua; del trabajo de Davenport-Hines me pareció especialmente sugerente sus explicaciones culturares sobre las problemáticas (más que soluciones) que conllevan las prohibiciones de mercancías embriagantes. Sobre los narcóticos en la filosofía, Walter Benjamin reflexionó extensivamente sobre sus experiencias en sus textos reunidos en On Hashish, en los que se destaca un lúcido ensayo sobre el opio titulado "Notas sobre el Crock"; Jacques Derrida contesta sobre las problemática de los narcóticos en un entrevista titulada "La retórica de la drogas", y lo mismo hace Michel Foucault en la entrevista "Sex, Power, and the Politics of Identity." Los libros Culture on Drugs de Dave Boothroyd y High culture, editado por Anna Alexander y Mark Roberts, son también trabajos muy ilustrativos sobre narcóticos y pensadores. La bibliografía, como decíamos, es extensa, iluminativa y diversa. La prohibición ha rodeado el opio: no el silencio. 
También juegan un papel fundamental para que los poetas se acerquen al opio y escriban sobre él las lecturas que ejecutaron Vallejo y Neruda de textos drogados de escritores de Europa e Hispanoamérica que testimoniaron sus experiencias narcóticas de variadas maneras: en ensayos, como Los paraísos artificiales (1860) de Charles Baudelaire, en confesiones-ensayos, como Confesiones de un opiómano inglés (1821) de Thomas De Quincey, en poemas, como el inaugural “Kubla Khan” (1816) de Samuel Taylor Coleridge, entre muchos otros formatos y escritores ${ }^{2}$. De Quincey gozó uno de sus momentos de mayor gloria editorial con la publicación de las Confesiones de un opiómano inglés (1821), que suele ser considerada como uno de los textos inaugurales de la literatura drogada y junto con los Paraísos artificiales (1860) de Baudelaire, que es una respuesta al texto de De Quincey, son los textos que han llevado a más escritores a experimentar con este narcótico, principalmente para poder escribir sobre su drogada experiencia. Neruda y Vallejo comparten con De Quincey la necesidad de escribir sobre la experiencia narcótica y la confesión del consumo, pero sobre todo coinciden en las maneras en que se sirven del opio para comentar asuntos para nada exclusivos a las experiencias drogadas. Su opio presenta relatos sobre amigos y enemigos, iguales y distintos, Asia, América y sus sueños, cercanías y distancias, que el opio lejos de disolver, resalta ${ }^{3}$. "Si un hombre que solo habla de bueyes se convierte en comedor de opio", asegura una de las más afamadas citas de las Confesiones, "lo más probable (a menos que sea demasiado obtuso para soñar) es que sueñe con bueyes" (16). El opio para los poetas no representa un narcótico promotor de igualdades, sino que sirve para resaltar diferencias y reforzar las divisiones poéticas y políticas. Confesión, ansias de infinito y separación son, por lo tanto, algunos conceptos que comparten estos distantes poetas que se relacionan con el opio, pues tanto Neruda como Vallejo, Baudelaire o De Quincey, son escritores que describen el uso personal del opio para dividir y distinguir clases sociales y culturas, inteligencias, estéticas y políticas, y destacan claramente esas separaciones usando la droga asiática como marcador ideal para destacar estas diferencias. El deseo literario de acercarse a poetas de esa estirpe, y otros de las Américas como Edgar Allan Poe, Rubén Darío, José Martí y Julián del Casal que

2 Los motivos que llevan a Vallejo y Neruda a fumar opio o emborracharse con vino son imposibles de perseguir y aclarar con seguridad, pero pienso que si no solo experimentaron sino que escribieron sobre sus drogas es para dialogar con los textos literarios drogados y formar parte de esa comunidad letrada y alucinada. Germán Labrador define en su libro Letras Arrebatadas como textos drogados "aquel texto poético o narrativo cuyo discurso se ve transpirado por la presencia de un fármaco psicoactivo, como marco narrativo, como sistema retórico y metafórico o como argumento o eje causal en su construcción"(48). El texto drogado "posee una poética propia, entendida ésta como un sistema lingüístico que comprende su propio léxico, su propio sistema metafórico, sus propios recursos estilísticos y los propios símbolos, es decir, como el lenguaje que permite identificar un texto como perteneciente a una tradición específica. Los textos drogados se hablan los unos a los otros y configuran por medio de la intertextualidad un universo semántico y lingüístico propio donde situarse y reconocerse como miembros de una misma estirpe" (Ibíd.). Los textos drogados de Vallejo y Neruda por muy singulares que sean dentro de la poesía de América latina, se relacionan fuertemente con esta "estirpe" que define Labrador.

3 En décadas posteriores, las novelas Junky (1953) y Naked Lunch (1959) de William Burroughs realizan una operación similar con la heroína, derivado del opio: la droga es utilizada como entrada narrativa privilegiada, por sus reglas, sus efectos, sus hábitos y rituales, sus resacas, para reflexionar sobre los más variados temas, para nada constreñido al narcótico. 
también experimentaron y escribieron sobre sus drogas, revela las ansias de Neruda y Vallejo de intentar recrear narcóticamente remotas colonias, sus exóticos productos y sobre todo poder soñar narcóticamente lo que soñaban los poetas que los anteceden ${ }^{4}$.

Por estas razones, el opio en Vallejo y Neruda muestra también cómo su exploración y evaluación de la droga es también una forma de describir lo asiático. Llama la atención que los testimonios narcóticos de Neruda y Vallejo sobre el opio, pese a la distancia temporal que separa sus composición, presentan una trama casi idéntica: un poeta que por melancolía, literatura o bohemia busca al opio, y al encontrarlo, se adentra en un espacio asiático que lo asombra: los fumaderos como representación de lo asiático. En ese espacio que mezcla la atracción exótica por la droga con una no menos exótica sobre lo asiático, la atención a la droga y a la melancolía de los poetas protagonistas pasan a un segundo plano, entregándole toda la atención narrativa a la evaluación de los lugares y personajes asiáticos. El opio, de esta manera, se muestra como una mercancía que iguala la ebriedad opiácea con un viaje a Asia, y también las imposiciones que por medio del rechazo al opio separa objetos, costumbres, comidas y bebidas, inclinando la balanza de lo limpio, sobrio, racional y bello en favor de los estándares de la burguesía occidental. En la descripción del opio de Neruda, por ejemplo, esta droga no es ni un lujo ni un viaje, pero al mismo tiempo, por medio del aborrecimiento que le declara a esta droga, el poeta termina por denigrar indistintamente a sus usuarios. Vallejo, más cercano en tiempo y estilo al modernismo en su relato drogado, evalúa al opio como una aproximación a lo desconocido del azar; pero en ambos poetas el narcótico aparece como un espacio imaginario de encuentro o desencuentro con lo asiático y muestra los mecanismos por los cuales evalúan este cruce. Lo que escriben los poetas de este trabajo sobre esta droga, por lo tanto, revela sus inquietudes subjetivas, políticas y estéticas que son a las que le daremos más atención en las páginas que siguen.

\section{César Vallejo: dados, destinos y opio en los fumaderos de Lima}

Vallejo borró literalmente la droga de su poesía. Una evidencia clara de esa voluntaria eliminación se observa en el poema "Encaje de fiebre" de la sección "Canciones de Hogar" que cierra Los heraldos negros (1919). Su versión original decía: "Porque antes de la Droga, que es hostia hecha de Ciencia, /está la hostia, Droga hecha de Providencia"

4 Además de la investigación de Marta Herrero-Gil sobre drogas y escritores modernistas, los trabajos de Jorge Camacho, "Los imaginarios de la droga, orientalismo y sexo en el poema "Haschisch" de José Martí", y de Hugo Viera, "El viaje modernista: la iniciación narcótica de la literatura hispanoamericana en el fin de siglo," son igualmente sugerentes en sus análisis. Rubén Darío escribió un cuento que relata diferentes historias a partir de diferentes bocanadas de humo embriagante: "El humo de la pipa" (1888). José Martí en su poema "Haschisch" hace de la resina de la marihuana un lugar de celebración poética por los efectos eróticos e imaginativos que produce. Un texto donde el narcótico habla en primera persona es el poema o traducción "La canción de la morfina” de Julián del Casal que aparece en su colección Hojas al Viento de (1890). Estos textos drogados han sido analizados con claridad por los estudiosos y estudiosa antes mencionados. 
(Obra poética 109). En la versión publicada en 1919 del mismo poema, la "Droga" con mayúscula es sustituida por una insípida "oblea”, con minúscula (Obra poética 108). Sobre esta significativa corrección editorial, notemos tres cosas relevantes: Primero, que la droga existía en la poesía de Vallejo y que fue intencionalmente arrancada de ella. Segundo, que desde antes de abogar por el marxismo y relacionarse activamente con sus conceptos, como lo hace en sus textos tardíos, Vallejo ya en Los heraldos negros comprendía y describía a la religión como un narcótico, pues describe a la hostia como una droga. Y tercero, que en la mutación de "Droga" con mayúscula a una simple "oblea”, con minúscula se transparenta la fuerza de la borradura, el deseo marcado de la desaparición y la denegación de la droga, incluso en desmedro del poema. En la Obra poética completa de César Vallejo, como mencionábamos anteriormente, aparece el opio nombrado una sola vez, en unas píldoras que atestiguan la alienación del espacio doméstico en el poema "Se estremecen las ventanas": "Ya no existe hogar sino en torno al velador del pariente enfermo, donde montan guardia impaciente, sus zapatos vacantes, sus cruces de repuesto, sus píldoras de opio" (313). La única presentación de esta droga en su poesía se hace exclusivamente a través de un formato médico-farmacéutico, no de ebriedad ni de inspiración poética. No hay más opio en su poesía, pese a que Vallejo fue asiduo de los fumaderos, y aunque tal vez los dejó de frecuentar en algún punto (o no), los conoció muy bien y tal vez por lo mismo en su relato se abstiene de hacer condena moralista hacia el narcótico y sus consumidores. "Hay un lugar que me sé/ en este mundo, nada más/ adonde nunca llegaremos” (Obra poética 295), anuncia el poema titulado "Trilce", que no incorporó Vallejo en su poemario homónimo de 1922 y que relata un viaje con sospechosos tintes narcóticos. ¿Tiene alguna relación el "Cráneo de bronce", título originario de Trilce, con la cabeza bronceada de la adormidera, flor del opio y por lo mismo con la composición del poemario más radical de Vallejo? Podemos solo especular, aunque no descabelladamente, esas posibilidades ${ }^{5}$. Con bastante unanimidad los biógrafos de Vallejo presentan las noches de bohemia en Lima como un momento relevante en la formación artística del poeta. La embriaguez, el deseo erótico y amoroso, los tormentos del por ese entonces joven Vallejo, se suelen destacar como sus duras inspiraciones iniciales que marcan al poeta y a su poesía. Jean Franco, por ejemplo, en su libro César Vallejo: La dialéctica de la poesía y el silencio, resalta que en 1918 Vallejo tenía un trabajo como profesor pero llevaba una "doble vida", pues si de día se dedicaba a la docencia, de noche era devoto de "cafés o incluso de excursiones a fumaderos de opio del barrio chino" (Franco 42). “ $\mathrm{Oh}$ mi bohemia de entonces!”

5 Los avatares de la vida de Vallejo son bastante más insignificantes que las inventivas de su poesía. En los poemas de Vallejo, sobre todo en Trilce, importan muy poco las aventuras o desventuras del escritor: mérito ciertamente de su poesía. En pocos poetas la biografía es tan nimia para nutrir un análisis como en la poesía de Vallejo, pues esta información no agrega más que un dato volátil sobre un terreno donde los datos, objetos y sujetos carecen de la seguridad de una clara referencialidad. Sus días de cárcel en la composición de Trilce es un oscuro ejemplo de esa disyuntiva que aclara muy poco la osadía poética de Vallejo. Ni la cárcel, ni el opio, ni la miseria económica ni nada explican Trilce, como tampoco nada explica Residencia en la tierra. 
se lamenta el poeta en "Cera" (123), pero también es sostenido conscientemente que los caminos del exceso pueden llevar, dolorosamente, a un vértigo que en el poeta es también una costosa sabiduría: "el círculo de mi cara libertad de hombre a dos aceras de realidad hasta por tres sienes de imposible" (123).

El cuento "Cera", que cierra el volumen de Escalas melografiadas (1923), será nuestra puerta de entrada para destacar, entre otros aspectos relevantes, puntos de conexión y de contrapunto con los testimonios de Neruda respecto al opio, y por medio de él a lo asiático. Como decíamos, ambos poetas comparten puntos claves en la trama de sus relatos: el acercarse al narcótico, contarlo desde su propia experiencia y experimentación, relacionarlo con secciones de sus vidas del pasado y asimismo el voluntario gesto de restarle activamente significación en la composición de sus trabajos poéticos. Pero sobre todo coinciden en consumirlo muchas veces, confesarlo y contar, aunque sea en muy pocas ocasiones, sus aventuras por escrito. El opio en Vallejo se vincula con lo asiático, pero en Lima, Perú, y se lo describe con personajes, calles y barrios con nombres propios. En su relato se muestra a alguien que ya conoce los fumaderos: no es un testimonio de "la primera vez", como lo es en Neruda. Por lo mismo, el cuento de Vallejo no arranca con la misma doble predisposición nerudiana de escribir su testimonio desde el asombro occidental para luego moralizar, también con patrones occidentales, costumbres de los trabajadores de Asia. El relato de Vallejo tampoco busca comprender o presentar esos extravíos desde una literatura anclada a la más tradicional moral burguesa: la prohibicionista, que impone costumbres, consumos y rechazos a partir de su moral y beneficios. Si la moral de la fábula del opio en Neruda es que el opio no es nada más que "un camino hacia el aniquilamiento" (120), y no cumple ninguna función en su trabajo, salvo el de importante marcador (negativo) de jerarquías y fronteras, en el relato de Vallejo, el opio es el objeto singular que abre un pasaje fugaz pero indispensable (precisamente por lo azaroso) para que el poeta enuncie uno de sus temas: la arbitrariedad del destino, expresada en el lanzamiento de los dados. Es decir, por medio del opio ingresamos a uno de los temas claves de la poética de Vallejo.

\section{El opio en los márgenes de la poesía y la política de Vallejo y Neruda}

Como sucede con los escritos sobre el opio de Vallejo y Neruda, los textos drogados suelen colocarse en segmentos menos reconocidos de las obras de los poetas pues parecen ser referencias marginales a sus principales atracciones y preocupaciones. No es extraño, por lo mismo que, de ser tratados en algún estudio, no pasan de ser referencias descriptivas de los textos mismos o simples anécdotas biográficas de los poetas. Si bien los textos drogados de Vallejo y Neruda se escriben en las periferias de sus principales obras, pienso que, precisamente por esa marginalidad, su valor es significativo y sobre todo productivo para analizar, pues puede develar o comprobar 
algunos perfiles menos explorados de estos importantes poetas. Salvo la borradura de la droga que precisamos anteriormente, Vallejo no se refiere al opio en su poesía, y eso que, al igual que Residencia en la tierra, incluye un número poco filtrado de objetos: zapatos, tenistas, anteojos, jueces, guano, cucharas, sonidos, etc. En los Reportajes y ensayos completos de Vallejo, el opio solo aparece citado bajo la condenatoria frase de Marx: "la religión es un opio del pueblo", en la cual, para atacar el efecto narcótico de las instituciones religiosas, injustificadamente el autor de El Capital (y en consecuencia Vallejo y Neruda) descalifica al opio, que lo deja sin más del otro lado de la contienda política, como objeto que marca y define el terreno del enemigo. Al acercarse a las políticas comunitarias, tanto Neruda como Vallejo insistirán en esta idea y representación del opio y de las drogas en general: como objetos alienante que marcan el lado antagónico de la demarcación política. Este dato es especialmente significativo en los testimonios de Neruda, pues los escribe bajo los efectos de esta nueva ideología. Vallejo escribe "Cera" en sus años bohemios, muy cercano en tiempo y aprecio al opio del que escribe. Por esto llama aún más la atención la radicalidad condena que hace Vallejo no solo del opio sino de todos los narcóticos como forma de resaltar su nueva concepción política. En su texto testimonial Rusia en 1931. Reflexiones al pie del Kremlin, además de reiterar la sentencia de Marx en contra de la religión, del opio y en favor de los soviets, también señala a las drogas como marcas divisorias: “¿Qué vida tan distinta a la de los obreros del capitalismo! Ni café, ni alcohol, ni juego de cartas, ni bostezos de aburrimiento" (Ensayos 76), siendo la diferencia entre los obreros soviéticos que celebra, y los del capitalismo, que considera explotados, precisamente sus drogas: "Nadie toma café ni siquiera en los desayunos. El ruso prefiere el té, que antes de la revolución se tomaba mucho, haciendo de ella una especie de droga" (Ibíd.) ${ }^{6}$. Opio, pero también alcohol, e incluso el té se destacan como sustancias narcóticas que separan a los trabajadores y los jerarquizan. El punto es claro: entre menos drogas, mejores obreros. Vallejo insiste en sus reportajes por tierras soviéticas

6 Vallejo prefería en estos momentos un completo despliegue de control estatal contra la embriaguez, incluso la del té: "El soviet lo ha dosificado, pero no con medidas traumáticas, sino poco a poco, por espontanea eliminación a base de propaganda y educación" (Ensayos 77).En vez de la simple prohibición, como en los Estados Unidos, con desastrosos resultados, Vallejo destaca que el "el leninismo es de una ductilidad desconcertante" (Ibíd.) y es por eso que a la "vigilancia policial" que caracteriza a la prohibición de alcohol y muchas drogas, se le contraponen en la Unión Soviética "propagandas entre las masas y la educación en las escuelas". De esta manera se "formaron innumerables ligas de combate" y la "profilaxis antialcohólica ganó rápidamente partidarios en los campos y en las fábricas", pues el estado mismo se encarga de asignar a esta política de persecución "un sitio preferente en sus planes anuales" (Ibíd.). Estos mecanismos de sobrio control estatal son evaluados por el poeta como "desconcertantes" por los asombrosos resultados que evidencia. Reporta: "la situación en este terreno en halagüeña" pues no solo "diariamente se suspende la venta de alcohol en numerosas aldeas, a solicitud de los mismo habitantes" (Ibíd.). Con un discurso no muy disfrazado, Vallejo aboga por un control prohibicionista de los narcóticos para beneficiar la producción laboral. Una actitud similar, de utilizar el opio como marca de separación política, es la que revelan los escritos de Neruda. En sus memorias señala: "Yo había pasado en 1928 por Hong Kong y Shanghái. Aquélla era una China férreamente colonizada; un paraíso de tabúres [sic], de fumadores de opio, de prostíbulos, de asaltantes nocturnos, de falsas duquesas rusas, de piratas del mar y de la tierra [...] Todos estos recuerdos regresaron a mi cabeza cuando llegué a la China de la Revolución. Este era un nuevo país, asombroso por su limpieza ética" (Confieso 308). 
que las drogas son una forma de división de las fuerzas productivas como también de sociedades enteras: las que distinguen al socialismo de sus enemigos. "Al amigo del alcohol se le considera como un tácito enemigo del socialismo", resalta el poeta (77). Pero Vallejo no siempre tuvo la misma relación negativa y distante con las drogas. Al igual que Neruda, las niega una vez que abraza la lucha emancipadora como clave de su trabajo poético, pero también, como también sucede con el poeta de Residencia en la tierra, Vallejo las experimenta muchas veces, y también las celebra, no de una forma incondicional, pero sí significativamente. El opio es el camino que lo lleva a atestiguar el azar de los dados, especialmente significativo en la poética de Vallejo. El único relato de Vallejo, titulado "Cera", en que se explaya con detalles sobre el opio aparece en sus bastante menos comentadas colecciones de cuentos. Publicado en la colección Escalas Melografiadas de 1923, un año después de Trilce y el año mismo en que parte a Europa para ya no volver más a América, "Cera", narra una historia que mezcla la búsqueda de opio, lo "chino" en Lima y lo azaroso de los encuentros que se abren gracias a la errante búsqueda del narcótico embriagante. En la prosa de Vallejo se demuestra el íntimo conocimiento que tenía el poeta del producto, de sus formas de consumo, de los efectos y de los lugares donde fumarlo, detallando las calles precisas de Lima donde se encuentra la droga, como también los nombres propios de los que lo atienden y lo suministran. En "Cera", el poeta-narrador no se somete de antemano a los prejuicios que suelen rodear las narraciones sobre el opio, y en cambio se adentra por medio de él a los laberintos del azar, a lo absurdo, a lo errático, que son a los lugares donde lo lleva la ebriedad. El opio es la inefable puerta de entada a ese borroso e inestable mundo al que se adentra el personaje de "Cera", un alter ego del poeta Vallejo.

\section{Caminando sin rumbo por los barrios asiáticos de la ciudad}

En "Cera", Vallejo resalta a dos personajes como principales focos de la narrativa: en un primer momento, al personaje central es un poeta acongojado que busca opio en los barrios chinos y narra sus desdichas; $y$ en un segundo momento, a Chale, un chino o mongol (se mencionan las dos variantes en el relato), que se describe por medio de lo que atestigua el poeta-narrador, que entregado a su destino errante, y buscando opio se encuentra con Chale en su fumadero y le pasa todo el protagonismo de la narración. Literalmente el opio es el objeto simbólico que hace que el relato pase de una narración ensimismada a la narración de la otredad. En el cuento, el personaje asiático acapara la admiración del narrador, y en él caen las virtudes que anhelaría un poeta: la de un secreto labrador y adiestrador de dados con los que se juega la fortuna y el destino en el arbitrario ejercicio del lanzamiento y las apuestas. Chale es un personaje que perfectamente podría ser el protagonista de su poema "Los dados eternos" de Los heraldos negros, donde declara: 


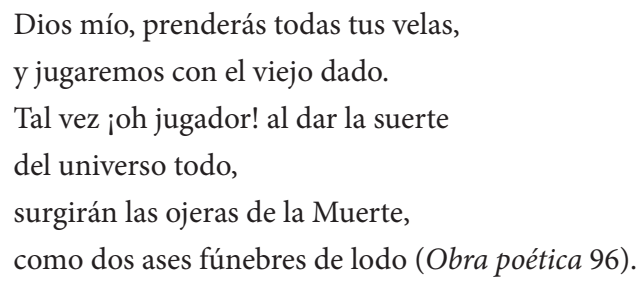

Si en la poética de Vallejo los dados reemplazan los poderes de Dios, de la gramática y del sentido, o los instalan en el plano del azar, lejos de la determinación, en este cuento, para llegar a al revelación de los dados se necesita anteriormente buscar al opio, que está en los barrios chinos de Lima. Antonio Merino en el "Estudio preliminar" a la Narrativa completa del poeta dice que "Cera", por un lado, se enlaza "con otros elementos y preocupaciones que encontramos en algunos poemas" de Vallejo, como "dados, azar, destino" (26), y también es un cuento que "ha sido considerado por parte de la crítica como un claro exponente del nihilismo de Vallejo, encontrando puntos de contacto con Un golpe de dados jamás abolirá el azar, de Mallarmé y los ecos de la inspiración de Así habló Zarathustra (Nietzsche)" (19). Tampoco es casual, indica Merino, "que Vallejo haya elegido lo chino (Chale, el jugador) como protagonista de la enajenación del individuo en una sociedad enferma" (27), pues los chinos, comenta Merino, "representan el escalafón más bajo de la sociedad peruana" (Ibíd.), ya que "sin conocer la lengua, ni las costumbres, ni las condiciones en las que iban a vivir, soportaban trabajos más duros y sustituían al indio en tareas más peligrosas" (28). De esta manera, precisa Merino, "llevados a la desesperación por la droga y el alcohol (sus únicos alimentos), muchos encontraban en el juego la única salida fácil para remediar su situación" (Ibíd.). "Cera”, pese a que la prosa preciosista se manifiesta incluso más notoriamente que en los versos más tempranos de Los heraldos negros, sobre todo en los arcaísmos de hacer pronombre enclítico en cada verbo del cuento (“dispúseme", "soldóse”, etc.), es un cuento que muestra también una fábula especialmente memorable: la historia de un personaje ebrio (el poeta), que se encuentra con un hombre puliendo y adiestrando unos dados en el barrio chino de Lima en los momentos en que busca opio, encuentro que asombra tanto al narrador que lo sigue en sus posteriores partidas y apuestas. La historia de Vallejo comienza así: "Aquella noche no pudimos fumar. Todos los ginkés de Lima estaban cerrados. Mi amigo, que conducíame por entre los taciturnos dédalos de la conocida mansión amarilla de la calle Hoyos, donde se dan numerosos fumaderos, despidióse por fin de mí" (123). El poeta solitario continúa su búsqueda del narcótico en los barrios chinos, donde confiesa melancólicamente su extravío: “Todavía me sentía un tanto ebrio de los últimos alcoholes. [...] cuando vime ya solo, caminando sin rumbo por los barrios asiáticos de la ciudad" (Ibíd.). Ebrio y sin rumbo por los barrios chinos, se refugia en la búsqueda del opio que pasa a ser la posible solución narcótica para su alivio y sueño: "Entonces no habría podido dormir. Imposible. Sufría el redolor de mi 
felicidad trunca", por lo que, confiesa "Quise entonces fumar. Necesitaba yo alivio para mi crisis nerviosa. Encaminéme al ginké de Chale, que estaba cerca” (Ibíd.). El opio es la ansiada medicina contra la desolación, los avatares de la existencia, y fumar opio es para el poeta un alivio y un refugio, pero también lo que lo lleva a los barrios chinos y al encuentro con lo asiático. El narrador, alter ego de Vallejo, sabe dónde encontrar el opio y la búsqueda de esa embriaguez es la principal metáfora que señala el autor de "Cera" en este relato, más que fumar y detallar los efectos de la droga, que nunca se describen. Al encontrar el lugar del opio, el relato luego se concentra exclusivamente en el azar de los dados de Chale y cómo lo atestigua el narrador por las ranuras que abre la búsqueda del opio: "Por la cerradura de la puerta alcancé a distinguir que Chale hacía luz, y sentábase con gran desplazamiento de malhumor delante de la lamparita de aceite, cuyo verdor patógeno soldóse en mustio semitono a la lámina facial del chino, soflamada de visible iracundia. Nadie más estaba allí” (Ibíd.).

El poeta-narrador entromete su mirada de testigo en la intimidad asiática y desde ahí desarrolla la segunda y más extensa parte del cuento. En los fumaderos de opio de Lima encuentra el narcótico que aliviará sus desdichas, pero es sobre todo la búsqueda del opio la que lleva al narrador a esa cerradura y la que lo conduce finalmente a la atractiva trastienda del azar:

consideré importuna mi presencia y resolví marcharme, cuando el asiático abrió uno de los cajones de la mesa y, capitaneando de alguna voz de mando interior e inexorable, que desenvainóle el cuerpo entero en resuelto avance, extrajo de un lacónico estuche de pulimentado cedro, unos cuerpos blancos entre las uñas lancinantes y asquerosas. Los puso en el borde de la mesa. Eran dos trozos de mármol. La curiosidad tentóme (123-4).

Un aspecto especialmente llamativo del relato es que nunca queda claro si el personaje fumó opio o no esa noche de extravío y ebriedad. La curiosa tentación del azar y lo asiático devora narrativamente la atracción hacia el opio, pues el narrador al ver por la cerradura a Chale puliendo y adiestrando los dados, el narcótico, que fue el que lo llevó hasta esa puerta secreta desaparece del relato la narrativa. El opio se hace humo en el cuento, y en la obra de Vallejo en general, pues no se menciona más el narcótico, y los dados de Chale, su diestro manejo y las dramáticas apuestas que realiza con ellos pasan a transformarse en el centro indiscutible del relato. Ese salto, de ir en búsqueda de un objeto transgresor y resaltar otro, azaroso, es una de las metáforas que deja el opio en "Cera", que aparece como el objeto conector y evanescente que lleva a esas curiosas puertas hacia lo desconocido. "El camino del exceso conduce a los palacios de la sabiduría” (31), precisa William Blake en The Marriage of Heaven and Hell?.

7 Mi traducción. El verso de William Blake dice "The road of excess leads to the palace of wisdom" en The Marriage of Heaven and Hell (31). 


\section{Llegar al azar por la cerradura del opio}

No hay más opio en este cuento ni en la obra de Vallejo, predominando el asombro y la admiración por el descubrimiento al que se llegó por las vías de esta droga. El narrador deja de ser protagonista y Chale toma la atención de la historia. La narración continúa "unas semana después de aquella noche" (125), la que el opio llevó a la cerradura, cuando escuchó historias sobre Chale y las dudas sobre la limpieza de su juego, pues suele ganar en las partidas grandes sumas de dinero en arriesgadas apuestas. Por lo mismo, una noche lo lanzó "la inquietud al antro donde jugaba Chale. Era una casa de juego para los más soberbios del tapete" (126). Pero incluso en el selecto grupo de jugadores, Chale se destaca sobre el resto por sus destrezas con los dados, tiradas que son descritas con especial fascinación, aparentando que más que de dados, se habla de poesía, del arrojo y los escalofríos de su ejecución:

Chale deshízose violentamente de los dados, como un par de brasas que chisporroteasen, y rugió una hienada formidable grosería que trascendió en la sala a carne muerta. Palpéme en mi propio cuerpo como buscándome, y me di cuenta de que allí estaba yo temblando de asombro. ¿Qué había sentido el chino? ¿Por qué arrojó los dados así, como si le hubiesen quemado o cortado las manos? (Ibíd.).

La historia de "Cera" termina sorpresivamente con la llegada de un hombre que "carecía de patria étnica" (129), y el que le apuesta a Chale todo lo que ha ganado esa noche en una sola partida, la que repentinamente se transforma en un juego por la vida. "El apostador único, solitario, sin que nadie, absolutamente nadie, menos el chino, pudiese advertirlo, extrajo del bolsillo su revólver, acercólo sigilosamente al cerebro de Chale, y, la mano en el gatillo, erecto el cañón hacia aquel blanco" (130). La encrucijada de la vida y la muerte es el lugar donde se mide la destreza y el arte de Chale: "Los mármoles corrieron y corrieron y corrieron. El cañón y el gatillo y la mano esperaban. El de la gran parada no miraba los dados: sólo miraba fija, terrible, implacablemente a la testa del asiático" ese "revólver contra ese par de dados que pintarían el número que pluga a la invencible sombra del Destino" (131). En este momento la narrativa sufre una breve pero significativa dislocación. Pese a que se narra esta escena con detalles y en primera persona, el narrador precisa que "cualquiera habría asegurado que yo estaba allí. Pero no. Yo no estaba alli’” (Ibíd.). El testigo cambia, pero no la historia, que termina dramáticamente: "Los dados detuviéronse. La muerte y el destino tiraron de todos los pelos. ¡Dos ases! El chino se echó a llorar como un niño" (Ibíd.). Escena especialmente cercana a la que describe en "Los dados eternos" antes citado, donde también el jugador "al dar la suerte/ del universo todo, /surgirán las ojeras de la Muerte, como dos ases fúnebres de lodo" (Obra poética 96). Si bien, como hemos visto, la mención al opio en "Cera" es breve y solo abre el relato, también notamos que es un elemento clave, y pese a que resalta un reclamo contra el ensimismamiento bohemio y drogado del protagonista y no son pocos los destellos 
exotistas con los que pinta las comunidades que rodean al opio, también se muestra el deseo de embriaguez que causa el opio como la posibilidad de entrada a nuevos mundos y destinos. El opio lleva al poeta-narrador a la cerradura de azar y a atestiguar desde ahí la apuesta que decide por medio del arte entre la vida o la muerte. Pero la marca del opio, permanente en la poesía Vallejo por esta conexión con el azar de los dados, se contrasta con la borradura que hace Neruda de este mismo narcótico, pues pese a que en ambos resaltan las concordancias de sus tramas, sobre todo la que pasa el foco de la búsqueda del opio a la evacuación de lo asiático, sus diferencias son también muy significativas.

\section{Neruda en Asia}

La relación de Neruda con el opio es reveladora desde dos perspectivas que deberían estar más relacionadas: por lo que escribió sobre su experiencia con esta droga y las consecuencias estéticas y políticas que podemos extraer de esos escritos, pero también por el lugar donde llevó a cabo esta experimentación: Asia. Predominan en las exégesis nerudianas y en confesiones sobre sus años en Asia (donde fuma muchas pipas de opio) las que distinguen a este periodo como una experiencia desolada que fue la principal inspiración de Residencia en la tierra. Por esto, Adam Feinstein, biógrafo de Neruda en lengua inglesa, titula como "Desolación asiática" (“Asian Desolation”) estos años en su biografía Pablo Neruda. A Passion or Life (51). El mismo Neruda en su biografía Confieso que he vivido denomina estos años como "La soledad luminosa" $(107)^{8}$. La miseria, la extranjería y la soledad del poeta se destacan una y otra vez como dolorosas fuentes creativas de Residencia ${ }^{9}$. Pero esta desolación es una que también muestra a un poeta que desprecia a sus sirvientes asiáticos, pues pese a que confiesa que le "sobraba el espacio en aquella casa diminuta", tenía en ella a "una cocinera javanesa, una vieja campesina, igualitaria y encantadora", y también "un boy, también javanés" que "servía a la mesa y limpiaba mi ropa. Allí terminé Residencia en la tierra" (Confieso 145). Rodeado de sirvientes, pero solitario, el poeta finaliza uno de sus libros más importantes. Como lo describe el mismo Neruda, en su estancia en Asia, los “orientales” no eran acompañantes para él, sino por el contrario, acentuaban la desolación y alienación que permea Residencia en la

8 Los estudios de Edmundo Olivares, Pablo Neruda: los caminos de Oriente y de Hernán Loyola: Neruda, La biografía literaria, son especialmente informativos sobre estos años asiáticos de Neruda, como también son ejemplo de la manera en que el dato de sus frecuentes aventuras con el opio aparece relativizado o silenciado por críticos que se caracterizan precisamente por detallar y destacar cada instancia del poeta.

9 En sus memorias poéticas y narrativas, Neruda se presenta como un sujeto de fronteras, de bordes, dislocado en los centros: narra que su infancia la pasó en la "frontera" sur de Chile, Temuco: entre colonos y nativos, que en Santiago, la capital, es el provinciano, y en Asia, como diplomático, era extranjero para los colonizadores y los colonos. En España o Europa era el americano; en México, el chileno, etc. El poeta se viste de informante de esa liminalidad y la explota como una de sus principales singularidades poéticas y subjetivas. 
tierra. Neruda declara que la "verdadera soledad la conocí en aquellos días y años de Wellawatha”, pues no tuvo "más compañía que una mesa y dos sillas, mi trabajo, mi perro, mi mangosta y el boy que me servía y regresaba a su aldea por la noche. Este hombre no era propiamente compañía", ya que "su condición de servidor oriental lo obligaba a ser más silencioso que una sombra" y no "era preciso ordenarle nada, pues todo lo tenía listo: mi comida en la mesa, mi ropa acabada de planchar, la botella de whisky en la veranda. Parecía que se le había olvidado el lenguaje. Sólo sabía sonreír con grandes dientes de caballo" (Confieso 123-4). Es decir, los sirvientes asiáticos están al final de la jerarquía de los objetos de la casa del poeta: sillas, mesas, perros, mangostas y por último, el sirviente. El modesto puesto diplomático no le impidió al solitario poeta tener una casa sobrada de espacio, llena de sirvientes, para que él pueda escribir, pagado por el gobierno de Chile, con whisky y opio servido por sus empleados, un libro sobre su propia e ensimismada desventura. Neruda se cansaba de ser hombre mientras una mujer le servía, otro limpiaba su ropa, daba whisky y otros le hacían las compras. "Estoy solo: cada diez minutos viene mi sirviente, Ratnaigh, viene cada diez minutos a rellenar mi vaso", le señala a Eandi sobre su desventurada vida de diplomático (Cit. en Loyola 390). No es extraño entonces que Neruda se identifique más exclusivamente con los colonizadores y se separe racial, intelectual y culturalmente de la forma más clara posible de los nativos del subcontinente Indio: "Todos los sirvientes roban en la India, y no se puede prescindir de ellos porque es mal mirado que la gente blanca haga cualquier cosa por sí misma. El blanco no debe comprar nada en el mercado o en la calle, de otra manera los nativos perderían su respeto" (Ibíd.).

Pienso que es importante desconfiar del reiterativo perfil desolado de Neruda en Asia, no solo por su dudosa desolación, sino porque también borra al opio y otras abyecciones que fueron parte significativa de sus experiencias en ese continente. Neruda le comentaba a Volodia Teitelboim que no tenía "apuro por escribir sobre la India y sobre Birmania y Ceilán”, de su experiencia de Asia porque muchas causas y componentes le "parecen ocultos, y muchos fenómenos, aun inexplicables. Todo parece en ruinas y despedazándose, pero en verdad, fuertes ligamentos elementales y vivientes unen estas apariencias con vínculos casi secretos y casi imperecederos" (Teitelboim 143). Pero el poeta sí escribe sobre ese continente, y mucho, y por lo por lo general muy negativamente, y hasta el final de su vida, sin dejar nunca sus marcados prejuicios. Neruda trasluce su rabia contra el colonialismo europeo por medio de su injusto rechazo a los nativos de Asia, y utiliza una y vez al opio como arma simbólica para dirigir este doble rechazo. 


\section{El opio no era el paraíso de los exotistas... sino la escapatoria de los explotados}

Neruda escribió una vastísima obra y sobre diversos temas, pero principalmente escribió sobre él mismo. En esa sintonía escribió también su experiencia con el opio de Asia ${ }^{10}$. Pero en realidad, como veremos, el narcótico no es más que una excusa para hablar de sí mismo y de su rechazo por algunas costumbres asiáticas y colonialistas. El encuentro de Neruda con la droga de Asia está marcado desde el principio por la atracción literaria y una acentuada curiosidad por el narcótico y sus alrededores. En sus dos textos autobiográficos principales, Confieso que he vivido (1974) y Memorial de Isla negra (1964), Neruda destaca su encuentro con el opio como algo breve, circunscrito a sus confusos años en Asia, insignificante, pese a que aparece recalcado significativamente en sus dos autobiografías. Dado también a que el poeta no otorga ningún dato claro, en su silencio declara que la experimentación narcótica no influye de ninguna forma la poética e imaginería de su libro más alucinado: Residencia en la tierra, que iba dando forma mientras fuma frecuentemente opio. Sin que mezcle en sus testimonios los efectos del opio con su poesía, Neruda no oculta su experiencia narcótica y escribe sobre sus drogas en diferentes momentos y formatos, no solo en las autobiografías antes mencionadas, donde se resaltan una sobresaliente sección que se titula "El opio" de Confieso que he vivido, y el poema "El opio en el Este", con que se abre la sección dedicada a Asia de Memorial de Isla negra, sino además cartas que escribe desde Asia a Héctor Eandi y sus crónicas de la época reunidas póstumamente en Para nacer he nacido o más recientemente en la colección de textos que Neruda escribe en Asia titulada Oriente. Estos dispersos escritos son creados en menor medida durante su estancia en Asia (cartas y crónicas) y mayoritariamente muchos años después (poemas y confesiones), por lo que su evaluación del opio y sus consecuencias también están teñidas por esa distancia subjetiva y temporal. Al igual que el relato de Vallejo, la secuencia narrativa de la mayoría de los textos de Neruda sigue la misma distintiva secuencia: curiosidad exotista inicial de un sujeto ensimismado, experimentación, exposición de sus efectos por escrito, asombro por lo asiático, pero a diferencia del texto de Vallejo, los de Neruda suelen concluir con un rechazo hacia el opio que exculpa al poeta de esa aventura narcótica. El poema de "El opio en el Este" destella la curiosidad inicial del poeta que relaciona al opio con el ingreso a Asia: "Ya desde Singapur se olía a opio", dice el primer el verso del poema que abre tanto el texto como la sección de poemas/memorias relacionados con ese continente. El opio es la puerta de entrada de Neruda a Asia. Tras esta apertura, el

10 En otro trabajo detallo con más detención y ejemplos los vínculos de Neruda con el opio de Asia: el valor artístico que se filtra en su poesía, el silencio de la crítica a lo que concierne al narcótico, también y el uso que le da el poeta como frontera política, son algunos de los temas que destaco en "Pablo Neruda y el opio (del pueblo).Reflexiones en torno a la "metafísica cubierta de amapolas" de Residencia en la tierra" (2016). 
poema prontamente da paso a la detallada descripción tanto de los efectos del opio, indicados en términos altamente poéticos, sensoriales y visionarios, como también de los que frecuentan los fumaderos, que en contraste con la brillante descripción de los efectos narcóticos, los presenta de manera muy negativa. Sobre los efectos, precisa el poema:

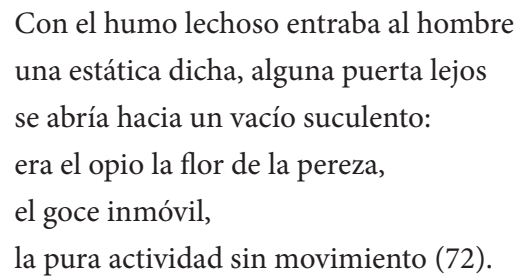

El opio permitía sumirse a una "estática dicha" que permite que se abra "alguna puerta" hacia un "vacío suculento", y desde ahí gozar la "pura actividad sin movimiento". Conceptos no muy lejanos a los que expone en su poema "Unidad" de Residencia en la tierra, escrito antes de su experimento con el opio, donde precisa que "Hay algo denso, unido, sentado en el fondo, /repitiendo su número, su señal idéntica", un "algo" que se reúne rodándolo" (45) En ese contradictorio trance de "goce inmóvil", Neruda continúa poetizando sobre sus efectos en "El opio en el Este" de esta manera:

Todo era puro o parecía puro,

todo en aceite y gozne resbalaba

hasta llegar a ser sólo existencia,

no ardía nada, ni lloraba nadie,

no había espacio para los tormentos

y no había carbón para la cólera (72).

No es difícil pensar que si estas mismas descripciones de efectos embriagantes del opio que llevan al poeta a ser "solo existencia" fueran representaciones que destilara Neruda sobre algún amor o encuentro erótico, y no sobre una droga exótica y condenada, al menos alguno de sus más destacados críticos se hubiera detenido en él y extraído sus consecuencias poéticas. Pero por el contrario, la experiencia del opio se cierra, silencia y condena con la confesión final del poeta que lo rechaza por su nimiedad poética, pero sobre todo por ser instrumento de la explotación colonial. Sin embargo, por estas mismas razones el opio en Neruda se representa como un objeto que si bien permanece alejado de su poesía (según la falta de indicaciones que da Neruda), también reluce como un poderoso marcador de terrenos fundamentales del mapa nerudiano. 


\section{El opio del pueblo}

En el poema "El opio en el Este", como en los otros textos en que Neruda se detiene sobre sus aventuras con el opio, muestra cómo la experiencia narcótica y sus efectos quedan finalmente supeditados a la verdadera visión que extrae el poeta de esta droga, y que si bien tiene relación con sus propiedad anestésica, sobre todo se destaca el hecho de que es usada como una droga de dominación colonial. La explotación colonial de la adormidera es lo más reiterativo de los reportes sobre el opio que hace Neruda, noción que los lleva a representar esta droga en sus escritos como una experiencia narcótica que pasa a enunciar una sentencia y denuncia política. Al igual que en el relato de Vallejo, en los testimonio de Neruda el opio mismo y los efectos subjetivos que produce pasan a un segundo plano narrativo para poner en primer plano la denuncia de la aniquilación humana y política como la verdadera y más perdurable característica que posee el opio. Para este acometido, Neruda pasa el foco de su poema del opio a los cuerpos que lo consumen. Así los describe en su poema de Memorial de Isla Negra:

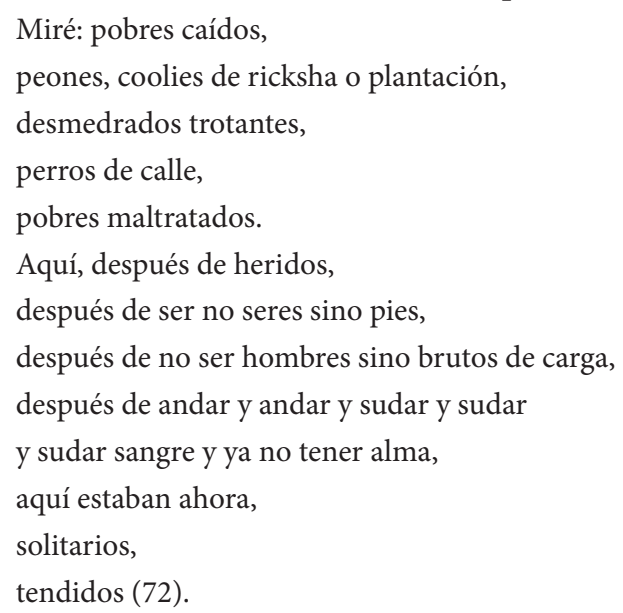

En los fumaderos de opio de Neruda no hay humanos, sino "perro de calle", personas que no son personas "sino pies" o "brutos de carga". Esa deshumanización que lleva el explotador trabajo colonial encuentra sus sostén, no su remedio o distancia, en los efectos del opio, que de la mano con los explotadores trabajos coloniales, trasforma los cuerpos humanos en objetos o peor aún, en desechos. Por eso, los que llegan ahí, "los pata dura",

cada uno con hambre había comprado

un oscuro derecho a la delicia,

y bajo la corola del letargo,

sueño o mentira, dicha o muerte, estaban

por fin en el reposo que busca todo vida,

respetados, por fin, en una estrella (73). 
Neruda puede percibir en los efectos del opio la posibilidad que tienen los trabajadores de alcanzar finalmente "el reposo que busca toda vida", de ser "respetados, por fin, en una estrella", aunque sea bajo los efectos de un "sueño o mentira, dicha o muerte". Sin embargo, en los testimonio sobre el opio de Neruda impera su visión aniquiladora y deshumanizadora de esta droga. Una vez que Neruda conoce íntimamente el opio, tras haber fumado muchas pipas, lo rechaza y condena definitivamente. Esa es finalmente su confesión y lo que ha perdurado como consecuencia de la aventura narcótica de Neruda: "Después de entonces no volví a los fumaderos... Ya sabía... Ya conocía... Ya había palpado algo inasible... remotamente escondido detrás del humo" (Confieso 119). Neruda además condena los fumaderos de opio por considerarlos un engaño literario, pues los fumaderos no eran para Neruda como se lo "habían pintado" o cómo él lo había leído: "No había ningún cojín bordado, ningún indicio de la menor riqueza" (120) como escribían los modernistas sobre sus efectos. "Nada brillaba en el recinto, ni siquiera los semi cerrados ojos de los fumadores" (Ibíd.). El poeta se acerca al opio esperando un total desarreglo que lo conduzca a visiones y encantos exotistas como entrada al mundo asiático, pero se desilusiona, y espantado de la falta de exotismo, lujos y alucinaciones, se encierra en su manifiesto rechazo: a la droga y a sus consumidores. Neruda aparta los efectos narcóticos del opio de su literatura, pero sobre todo él mismo se distancia de los trabajadores de Asia que lo consumen, pues no son "seres sino pies" ("El opio en el Este" 72). El rechazo estético hacia al opio que devela Neruda, lo distingue poéticamente de los modernistas u otros artistas experimentales que usaron al opio como inspiración, pero también este rechazo se mezcla inseparablemente con su abominación a los "pobres caídos" de Asia. El opio, por lo tanto, más que una droga singular y de fuertes inspiraciones literarias, pasa a escenificar el desprecio generalizado que expresa constantemente Neruda por lo asiático. En "El opio en el Este" los que fuman esta droga son yacentes, pata dura, los hambrientos, los peores caídos, los desmedrados, los brutos de carga, los maltratados, solitarios, los perros de la calle, y no deja de ser significativo que el poeta dedique muchas más palabras (casi todas con connotaciones fuertemente negativas) para describir a sus consumidores que a la descripción de los efectos del opio. Si este narcótico permitía a los trabajadores comprar un "respeto" y "reposo" momentáneo, Neruda pareciera querer despojarlos de ese fugaz beneficio por medio de su insultante descripción de sus cuerpos y costumbres. De esta forma, el opio representa uno de los marcadores principales que utiliza Neruda para distanciarse de los trabajadores de Asia y el narcótico es empleado como un objeto clave para remarcar una línea de divisoria que distingue y jerarquiza estéticas y también clases sociales. En todas las referencias que el poeta escribe sobre el opio, el exótico narcótico aparece mostrado como un objeto alienante que revela la cara deshumanizadora de la explotación colonialista, pues transforma en muertos vivientes a las personas, y es el poeta el que denuncia lo que se esconde realmente tras los placeres del humo: "Comprendí por qué los peones de plantación, los jornaleros, los rickshamen que tiran y tiran del ricksha todo el día, se 
quedaban allí de pronto, oscurecidos, inmóviles" (Confieso 120). El opio adormece al pueblo y no tiene nada que ver con el arte y menos con la política emancipadora, salvo ser su enemigo declarado, marcar el otro lado de la línea de antagonismo. El opio, pese a "formar parte de un todo, de una rebosante delicia", no resulta para el poeta de Residencia un posible camino para soñar o descansar con los explotados, como fuera para los modernistas. A diferencia de lo que trasluce el relato narcótico de Vallejo, el opio para Neruda no es una instancia de encuentro alucinado, sino que los fumaderos eran solo "un camino hacia el aniquilamiento" (Ibíd.) y el poeta no muestra ninguna simpatía por "aquellos que soñaban con los ojos entrecerrados" que "estaban viviendo una hora sumergida debajo del mar, una noche entera en una colina, gozando de un reposo sutil y deleitoso" (Ibíd.). En los momentos en que Neruda escribe estas vivencias, muy posteriores a su consumo, el poeta oponía insistentemente la vigilia activa y sobria de la política emancipadora heroica a la ebria pasividad del goce de las drogas. De esta manera, el opio, en la biografía y la obra de Neruda, queda solo como parte de un pasado del cual el poeta se distancia y rechaza. Como hemos dicho, gran parte de los testimonios de Neruda sobre el opio se desarrollan cuando se ha volcado a una poesía comunitaria y el poeta trasformado en un líder poético. Sin embargo, pese a estar dedicado a escribir para los explotados e inspirándose en sus desventuras, Neruda no puede apreciar en el opio una forma de comunicación entre el poeta y los trabajadores, comunicación que supuestamente define su poesía en los momentos en que escribe sobre el opio.

Ahora bien, pese a toda la carga negativa que el poeta le vierte al narcótico, no podemos dejar de resaltar un rasgo fundamental de la experiencia nerudiana y es el importante hecho de que Neruda fumó el opio muchas veces, y no solo lo rechazó. Un detalle no menor que lo separa de sus correligionarios posteriores que solo se concentran en la prohibición y condena, y en ubicar el opio en el terreno del enemigo, pero sin ni siquiera conocerlo.

\section{Desenlaces del opio en Vallejo y Neruda}

Como hemos podido apreciar, el opio en los trabajos de Vallejo y Neruda representa una singular puerta de entrada para entender la complejidad de sus poéticas y sus comentarios políticos, pues esta droga no solo es un privilegiado marcador de los años formativos y bohemios de los poetas, sus rutas del exceso como espacio de inspiración y formación poética, sino además un marcador no menos privilegiado de la composición de sus subjetividades poéticas y políticas. En el caso de Neruda, en específico su relación con el opio, como parcial metonimia de su compleja y principalmente negativa relación con Asia, resalta uno de sus peores perfiles, pues sus años en Asia se representan en sus escritos como momentos muy negativos, los que junto con las múltiples pipas de opio que fumó en ese entonces, quedarán para siempre marcados como acciones de 
un pasado al que no se busca volver. Vallejo, por su parte, también se adentró en los vericuetos del opio y asomó en sus efectos una singular apreciación sobre lo asiático en Lima. El poeta de Trilce presenta el opio no solo desde la condena, sino también como una puerta a lo desconocido, como un narcótico que tiene la potencia de crear relaciones no completamente cartografiadas ni moralizadas de antemano, pues es una droga que, como resalta "Cera", marca desplazamientos y azares del destino que dejaban perplejo al poeta de Los heraldos negros. Vallejo y Neruda no celebran el opio como una panacea de la poesía. Por el contrario: no entregan ningún dato claro de cómo filtraron el opio en sus libros más radicales. Pero el opio es también un objeto que los distingue, pues en sus testimonios sobre esta droga revelan cada uno posibilidades muy distintas: el azar en Vallejo, la condena y el aniquilamiento en Neruda. El opio, por tanto, representa un escenario que vincula a estos poetas, pero también, y como signo que se reitera en el opio: los separa y distingue. Más tarde en sus vidas, para ambos poetas el opio no será más que otra soporífera religión de las masas, un enemigo político y por lo tanto poético. Vallejo y Neruda separaron su experiencia narcótica de su poesía al negarnos cualquier testimonio sobre esta relación, pero aun así, por medio de los textos que escribieron sobre sus experiencias con el opio podemos notar que esa aventura narcótica se permea en sus obras y subjetividades y señala las formas en que estos poetas relacionan conceptos poéticos con prejuicios, y también sus significativos y permanentes viajes por Asia.

\section{Referencias}

Alexander, Anna y Mark S. Roberts. High Cultures. Reflections on Addictions and Modernity. New York: State University of New York Press, 2003. Medio impreso. Baudelaire, Charles. Los paraísos artificiales. El vino y el hachís. Trad. Enrique López Castellón Madrid: M.E., 1994. Medio impreso.

Benjamin, Walter. On Hashish. Cambridge: Harvard University Press, 2006. Medio impreso.

Blake, William. The Marriage of Heaven and Hell. New York: Dover, 1994. Medio impreso. Boon, Marcus. The Road of Excess. A History of Writers on Drugs. Cambridge: Harvard University Press, 2001. Medio impreso.

Dave Boothroyd. Culture on Drugs. Narco-Cultural Studies of High Modernity. Manchester: Manchester University Press, 2003. Medio impreso.

Camacho, Jorge. "Los imaginarios de la droga, orientalismo y sexo en el poema "Haschisch" de José Martí". La Habana elegante 49 (primavera/verano 2011). www.habanaelegante.com/Spring_Summer_2011/Invitation_Camacho. Fecha de ingreso: 20 de marzo de 2015. Sitio Web.

Escohotado, Antonio. Historia general de las drogas. Madrid: Espasa-Calpe, 2008. Medio impreso. 
Davenport-Hines, Richard. La búsqueda del olvido. Historia global de las drogas. 1500 2000. México: Fondo de Cultura Económica, 2003. Medio impreso.

De Quincey, Thomas. Confesiones de un opiómano inglés. Trad. Daniela Gutiérrez. Buenos Aires: Zorzal, 2006. Medio impreso.

Derrida, Jacques. "Retórica de las drogas". Trad. Bruno Mazzoldi. Revista colombiana de psicología 4 (1995):33-44. Medio impreso.

Feinstein, Adam. Pablo Neruda. A passion for a Life. New: York: Bloombury, 2004. Medio impreso.

Fernandez Labbé, Marcos. "Del ficticio entusiasmo: el mercado de las drogas en el tránsito a la prohibición en Chile. 1920-1960”. Historia Critica 39 (2009): 62 83. Medio impreso.

Michel Foucault, "Sex, Power, and the Politics of Identity" (1982). Michel Focault. Ethics, Subjectivity and Truth. Essential Works of Foucault 1954-1984. Ed. Paul Rabinow. New York: The New Press, 1997. 163-173. Medio impreso.

Herrero-Gil, Marta. El paraíso de los escritores ebrios. La literatura drogada española e hispanoamericana desde el modernismo a la posmodernidad. Madrid: Amargord, 2007. Medio impreso.

Labrador Méndez, Germán. Letras arrebatadas. Poesía y química en la transición española. Madrid: Editorial Devenir, 2009. Medio impreso.

Loyola, Hernán. Neruda: La biografía literaria. Santiago: Seix Barral, 2006. Medio impreso.

Merino, Antonio. Estudio Preliminar. Narrativa completa. César Vallejo. Madrid: Akal, 1996. 5-60. Medio impreso.

Neruda, Pablo. Confieso que he vivido. Barcelona: Plaza \& Janés, 2002. Medio impreso.

---. Residencia en la tierra. Santiago: Universitaria, 2004. Medio impreso.

---. Memorial de isla negra. Barcelona: Random House, 2004. Medio impreso.

---. Oriente. Barcelona, Littera Books, 2004. Medio impreso.

Olivares, Edmundo. Pablo Neruda: los caminos de Oriente. Santiago: LOM, 2000. Medio impreso.

Parker, Cynthia y Michael Horowitz. Sisters of the Extreme: Women Writing on the Drug Experience. San Francisco: Park Street Press, 2000. Medio impreso.

Plant, Sadie. Writing on drugs. London: Faber Faber, 1999. Medio impreso.

Teitelboim, Volodia. Neruda. Santiago: Bat, 1991. Medio impreso.

Vallejo, César. Obra poética. Coord. Américo Ferrari. Madrid, Fondo de Cultura Económica, 1996. Medio impreso.

---. “Cera”. Narrativa completa. Ed. Antonio Merino. Madrid: Akal, 1996. 123-131. Medio impreso.

---. Ensayos y Reportajes Completos. Edición, estudio preliminar y notas de Manuel Miguel de Priego. Lima: Pontificia Universidad Católica del Perú, 2002. Medio impreso. 
Viera, Hugo. "El viaje modernista: la iniciación narcótica de la literatura hispanoamericana en el fin de siglo," Ciberletras. Journal of literary Criticism and Culture 2003. www.lehman.cuny.edu/ciberletras/v09/viera. Fecha de ingreso: 20 de marzo de 2015. Sitio Web.

Yurkievich, Saúl. Fundadores de la nueva poesía latinoamericana. Barcelona: Seix Barral, 1970. Medio impreso.

Recibido: 11 abril 2013

Aceptado: 31 agosto 2015 